\title{
Cariogenic Dietary and Toothbrushing Practices of Children during the COVID-19 Outbreak
}

\author{
Damla Akşit-Bıçak ${ }^{1, *}$ iD \\ ${ }^{1}$ Near East University, Faculty of Dentistry, Department of Pediatric Dentistry, Nicosia, Mersin 10, Turkey
}

* Corresponding author: Damla Akșit-Bıçak, Near East University, Faculty of Dentistry, Department of Pediatric Dentistry, Nicosia, Mersin 10, Turkey. Tel: +903922236464; Email: damlaaksit@gmail.com

Received 2020 December 15; Revised 2021 February 05; Accepted 2021 February 17.

\begin{abstract}
Background: The implemented COVID-19 prevention measures exert negative effects on children's nutrition and education, with approximately 1.5 billion children kept away from schools during this time.

Objectives: The present study aimed to assess the changes in toothbrushing and cariogenic dietary practices of children who spent most of their time at home during the COVID-19 pandemic.

Methods: The study was conducted on parents with children aged 1-15 years in Turkey from 1-26 May 2020 which was a period of confinement and self-isolation. A web-based questionnaire was prepared and distributed via email and social media upon the request of parents. The questionnaire consisted of 10 items divided into three parts. The first part of the questionnaire included items regarding the demographic data of the parents and children, the second part contained some items about the cariogenic dietary practices of children, and the last part encompassed items on children's toothbrushing frequency before and during the outbreak. Statistical analyses were performed using the Number Cruncher Statistical Systems (NCSS) software.

Results: A total of 1013 questionnaires were incorporated into the final analysis. Based on the results, children's intake of jam, honey, and molasses increased; nonetheless, their intake of sugar-sweetened, fruit-flavored juices, flavored milk, candy, and chocolate reduced during the COVID-19 outbreak ( $\mathrm{P}<0.05)$. Moreover, no difference was found in the consumption frequencies of other foods and the frequency of toothbrushing of the children before and after the COVID-19 outbreak $(P>0.05)$.

Conclusion: As evidenced by the obtained results, the cariogenic food consumption of children was not high and even decreased during the pandemic. Although not perfect, it is evident that parents did not experience much trouble managing their children's consumption of cariogenic foods and beverages during the time spent at home.
\end{abstract}

Keywords: Children, COVID-19, Coronavirus, Dental caries, Diet, Oral health, Questionnaire, Toothbrushing

\section{Background}

Severe acute respiratory syndrome coronavirus2 (SARS-CoV-2) is an extremely transmissible virus that emerged from Wuhan, China, and spread all over the world at the end of December 2019. The World Health Organization (WHO) named the disease caused by this viral, zoonotic, new pathogen as "Coronavirus Disease 2019" (COVID-19) (1). In Turkey, the first patient with COVID-19 was diagnosed in March 2020, with COVID-19 cases detected throughout the country from this date onward (2). Since COVID-19 is highly contagious and can be transmitted via respiratory droplets, it was crucial to prevent the spread of the virus in a fight against the disease. Therefore, social isolation and quarantine practices were implemented in many countries, including Turkey, resulting in the closure of schools (3). COVID-19 cases are less common and symptoms are milder in the pediatric population, compared to the rates reported in adults. Nonetheless, The implemented COVID-19 prevention measures exert negative effects on children's nutrition and education, with approximately 1.5 billion children kept away from schools during this time (4). Children fulfill approximately two-thirds of their daily nutritional needs in schools and kindergartens, with meals and snacks generally considered to be healthier in these environments, compared to those brought from home. Therefore, during the COVID-19 pandemic, a change was expected in the daily dietary practices of children (5).

During the COVID-19 pandemic, a balanced and healthy diet was recommended to protect the general health and support the immune system. Furthermore, it was also recommended to avoid giving sugary foods to children, and it was considered important to restrict the consumption of sweets and sugary drinks, such as flavored milk drinks, fizzy drinks, and sugarsweetened fruit-flavored juices $(6,7)$. Healthy dietary practices during this pandemic are not only necessary for children's general health but are also needed for the protection of oral and dental health (8). Diet plays a crucial role in the occurrence of dental caries since sticky foods and sugars make the oral environment more prone to dental caries. Consequently, serious attempts should be made to decrease the consumption of sticky foods and refined carbohydrates. In this respect, it is necessary to

Copyright (c) 2021, Author(s). This is an open-access article distributed under the terms of the Creative Commons Attribution-NonCommercial 4.0 International License (http://creativecommons.org/licenses/by-nc/4.0/) which permits copy and redistribute the material just in noncommercial usages, provided the original work is properly cited 
inform parents about the cariogenic properties of various foods $(8,9)$.

Dentistry procedures are aerosol-producing processes and increase the risk of infection for dental teams and pediatric patients during the COVID-19 outbreak (10). Therefore, to decrease the risk of cross-infection and transmission of the disease, only urgent dental treatments were performed, while elective treatments, including dental treatment under general anesthesia, were postponed during the outbreak $(11,12)$. This information highlights the necessity of preventive measures, such as healthy dietary habits and regular toothbrushing, in order to prevent dental caries occurrence during the pandemic.

\section{Objectives}

In light of the aforementioned issues, the current study aimed to assess the changes in cariogenic dietary practices of children who spent most of their time at home during the COVID-19 pandemic and examine their toothbrushing practices. The current study hypothesized that changes in the daily routine of children would increase their cariogenic dietary intake, potentially negatively affecting their oral health. Children's sugar consumption can be controlled more easily in schools due to the rules and specific routines, while parents may experience trouble managing their children's consumption of sugary foods and beverages during their time spent at home.

\section{Methods}

Ethical approval for this study was obtained from the Research Ethics Committee of Near East University (NEU/2020/79-1084). A web-based questionnaire in the Turkish language was prepared using Google Forms (Google LLC, Menlo Park, CA, USA). A requisition note which explained the aims and inclusion criteria of the study was attached to the questionnaire. The inclusion criteria entailed parents of children aged 1-15 years and willingness to participate. Initially, the questionnaire was piloted on 10 parents in order to improve feasibility and clarity. These responses were not considered in the final analysis. Questionnaires were found comprehendible and only underwent minor changes. Two groups of participants were included in this study. The first group included 14 parents of children who attended the Near East University, Department of Pediatric Dentistry for urgent dental treatment needs. The questionnaire link was sent to this group via e-mail. On the other hand, the participants in the second group were invited to participate by social media (Facebook and WhatsApp) using the snowball sampling technique. The anonymity of the participants was observed during and after data collection. Data collection was carried out between 1 and 26 May 2020, which was a period of confinement and self-isolation.

The questionnaire was statistically validated, and the minimum sample size was detected using the $\mathrm{G}^{*}$ power software (version 3.1) according to previous research (13). The total number of participants was calculated at 220 with a test power of 0.80 . The questionnaire was self-administered and consisted of 10 items divided into three parts. The first part of the questionnaire included items regarding the demographic data of parents and children, such as age, gender, and parental status. In addition, the parents were asked whether their children attended school before the outbreak and whether the frequency of the cariogenic food consumption of their children increased while staying at home during the outbreak. In the second part of the questionnaire, they were asked about the cariogenic dietary practices of their children before and after the COVID-19 pandemic. Children's consumption frequency of the following during the outbreak was also enquired about: fizzy drinks, sugar-sweetened fruit-flavored juices, flavored milk, chocolates, salty and sugary snacks, candies, honey, jam, and molasses. The last part of the questionnaire asked the parents about their children's toothbrushing frequency before and during the outbreak, and also asked for parental opinions and suggestions.

\subsection{Statistical Analysis}

Statistical analyses were performed using the Number Cruncher Statistical Systems (NCSS) software using descriptive statistics (i.e., mean, standard deviation, frequency, and percentage distributions). Moreover, McNemar's test was employed in repeated measurements of qualitative data. A p-value less than 0.05 was considered statistically significant.

\section{Results}

A total of 1,016 parents participated in the current study. After checking the returned questionnaires, three cases were excluded since their children were not within the specified age range. Therefore, a total of 1,013 questionnaires were included in the final analysis. The majority of participants (96.54\%) were mothers. The mean age of children was reported as $6.27 \pm 2.70$ years. Out of the children, 526 (51.92\%) cases were male with a mean age of $6.35 \pm 2.86$ years, and $487(48.08 \%)$ cases were female with a mean age of $6.19 \pm 2.52$ years. A number of $802(79.17 \%)$ children attended school or kindergarten before the COVID-19 outbreak, and 211 (20.83\%) cases did not. Based on the results, 454 (44.82\%) parents thought that their children's cariogenic food (i.e., snacks, candy, and chocolate) consumption frequency 
increased while staying at home during the COVID-19 outbreak.

The differences between the consumption frequencies of various cariogenic foods before and during the COVID-19 outbreak are displayed in Table 1. Foods with increased consumption during the outbreak included jam, honey, and molasses, and both responses of "once a day" and "many times a day" increased according to the frequency distributions of these foods $(\mathrm{P}=0.011)$. On the other hand, the intake of sugar-sweetened, fruit-flavored juices, sugar-sweetened, flavored milk, candy, lollipops, and chocolate was reduced, according to a statistically significant increase in "never" responses to the frequency distributions of children's consumption of these foods $(\mathrm{P}=0.0001)$. The "never" and "once a week" responses increased among the children before and during the COVID-19 outbreak according to the frequency distribution of chocolate consumption $(\mathrm{P}=0.0001)$, while no differences were found in the consumption frequency distribution of fizzy drinks $(\mathrm{P}=0.398)$, chips and salty snacks $(\mathrm{P}=0.08)$, as well as sugar-sweetened biscuits and cakes $(\mathrm{P}=0.132)$.

Table 2 illustrates the changes in the children's nutrient consumption frequencies during the COVID19 outbreak, as compared to before. It was observed that the consumption frequency of cariogenic foods remained the same at rates ranging from 65.15\%$86.18 \%$ during the COVID-19 outbreak, compared to before. Table 3 depicts children's toothbrushing frequency before and during the COVID-19 outbreak. As demonstrated in this table, no statistically significant differences were observed between the frequency of children's toothbrushing before and after the COVID-19 outbreak $(\mathrm{P}=0.583)$.

\begin{tabular}{|c|c|c|c|c|c|c|}
\hline & \multirow[t]{2}{*}{ Frequency } & \multicolumn{2}{|c|}{$\begin{array}{c}\text { Before COVID-19 } \\
\text { Outbreak }\end{array}$} & \multicolumn{2}{|c|}{$\begin{array}{l}\text { During COVID-19 } \\
\text { Outbreak }\end{array}$} & \multirow[t]{2}{*}{$\mathbf{p} \neq$} \\
\hline & & $\mathbf{n}$ & $\%$ & $\mathbf{n}$ & $\%$ & \\
\hline \multirow{5}{*}{ Fizzy drinks } & Never & 673 & 66.44 & 669 & 66.04 & \multirow{5}{*}{0.398} \\
\hline & Once a week & 242 & 23.89 & 231 & 22.80 & \\
\hline & Several times a week & 85 & 8.39 & 98 & 9.67 & \\
\hline & Once a day & 13 & 1.28 & 14 & 1.38 & \\
\hline & Many times a day & 0 & 0.00 & 1 & 0.10 & \\
\hline \multirow{5}{*}{$\begin{array}{l}\text { Sugar-sweetened, fruit-flavored } \\
\text { juices }\end{array}$} & Never & 524 & 51.73 & 597 & 58.93 & \multirow{5}{*}{0.0001} \\
\hline & Once a week & 307 & 30.31 & 259 & 25.57 & \\
\hline & Several times a week & 145 & 14.31 & 129 & 12.73 & \\
\hline & Once a day & 34 & 3.36 & 24 & 2.37 & \\
\hline & Many times a day & 3 & 0.30 & 4 & 0.39 & \\
\hline \multirow{5}{*}{ Sugar-sweetened, flavored milk } & Never & 533 & 52.62 & 626 & 61.80 & \multirow{5}{*}{0.0001} \\
\hline & Once a week & 273 & 26.95 & 219 & 21.62 & \\
\hline & Several times a week & 162 & 15.99 & 129 & 12.73 & \\
\hline & Once a day & 39 & 3.85 & 33 & 3.26 & \\
\hline & Many times a day & 6 & 0.59 & 6 & 0.59 & \\
\hline \multirow{5}{*}{ Chocolate } & Never & 60 & 5.92 & 90 & 8.88 & \multirow{5}{*}{0.0001} \\
\hline & Once a week & 361 & 35.64 & 383 & 37.81 & \\
\hline & Several times a week & 466 & 46.00 & 409 & 40.38 & \\
\hline & Once a day & 114 & 11.25 & 107 & 10.56 & \\
\hline & Many times a day & 12 & 1.18 & 24 & 2.37 & \\
\hline \multirow{5}{*}{ Chips and salty snacks } & Never & 340 & 33.56 & 366 & 36.13 & \multirow{5}{*}{0.08} \\
\hline & Once a week & 449 & 44.32 & 407 & 40.18 & \\
\hline & Several times a week & 195 & 19.25 & 205 & 20.24 & \\
\hline & Once a day & 26 & 2.57 & 25 & 2.47 & \\
\hline & Many times a day & 3 & 0.30 & 10 & 0.99 & \\
\hline \multirow{5}{*}{ Candy and lollipops } & Never & 406 & 40.08 & 477 & 47.09 & \multirow{5}{*}{0.0001} \\
\hline & Once a week & 420 & 41.46 & 359 & 35.44 & \\
\hline & Several times a week & 160 & 15.79 & 142 & 14.02 & \\
\hline & Once a day & 24 & 2.37 & 24 & 2.37 & \\
\hline & Many times a day & 3 & 0.30 & 11 & 1.09 & \\
\hline \multirow{5}{*}{$\begin{array}{l}\text { Sugar-sweetened biscuits and } \\
\text { cakes }\end{array}$} & Never & 124 & 12.24 & 139 & 13.72 & \multirow{5}{*}{0.132} \\
\hline & Once a week & 452 & 44.62 & 411 & 40.57 & \\
\hline & Several times a week & 367 & 36.23 & 383 & 37.81 & \\
\hline & Once a day & 65 & 6.42 & 66 & 6.52 & \\
\hline & Many times a day & 5 & 0.49 & 14 & 1.38 & \\
\hline \multirow{5}{*}{ Honey, jam, and molasses } & Never & 155 & 15.45 & 171 & 17.05 & \multirow{5}{*}{0.011} \\
\hline & Once a week & 208 & 20.74 & 184 & 18.34 & \\
\hline & Several times a week & 396 & 39.48 & 382 & 38.09 & \\
\hline & Once a day & 215 & 21.44 & 235 & 23.43 & \\
\hline & Many times a day & 29 & 2.89 & 31 & 3.09 & \\
\hline
\end{tabular}




\begin{tabular}{|c|c|c|c|}
\hline & Frequency change & n & $\%$ \\
\hline \multirow{3}{*}{ Fizzy drinks } & Same & 873 & 86.18 \\
\hline & Decreased & 60 & 5.92 \\
\hline & Increased & 80 & 7.90 \\
\hline \multirow{3}{*}{$\begin{array}{l}\text { Sugar-sweetened, } \\
\text { fruit-flavored juices }\end{array}$} & Same & 745 & 73.54 \\
\hline & Decreased & 169 & 16.68 \\
\hline & Increased & 99 & 9.77 \\
\hline \multirow{3}{*}{$\begin{array}{l}\text { Sugar-sweetened, } \\
\text { flavored milk }\end{array}$} & Same & 777 & 76.70 \\
\hline & Decreased & 196 & 19.35 \\
\hline & Increased & 40 & 3.95 \\
\hline \multirow{3}{*}{ Chocolate } & Same & 660 & 65.15 \\
\hline & Decreased & 205 & 20.24 \\
\hline & Increased & 148 & 14.61 \\
\hline \multirow{3}{*}{ Chips and salty snacks } & Same & 724 & 71.47 \\
\hline & Decreased & 143 & 14.12 \\
\hline & Increased & 146 & 14.41 \\
\hline \multirow{3}{*}{ Candy, lollipop } & Same & 734 & 72.46 \\
\hline & Decreased & 166 & 16.39 \\
\hline & Increased & 113 & 11.15 \\
\hline \multirow{3}{*}{$\begin{array}{l}\text { Sugar-sweetened } \\
\text { biscuits and cakes }\end{array}$} & Same & 691 & 68.21 \\
\hline & Decreased & 174 & 17.18 \\
\hline & Increased & 148 & 14.61 \\
\hline \multirow{3}{*}{$\begin{array}{l}\text { Honey, jam, and } \\
\text { molasses }\end{array}$} & Same & 740 & 73.78 \\
\hline & Decreased & 122 & 12.16 \\
\hline & Increased & 141 & 14.06 \\
\hline
\end{tabular}

Table 3. Children's toothbrushing frequency before and during the COVID-19 outbreak

\begin{tabular}{lccccc}
\hline \multirow{2}{*}{ Frequency } & \multicolumn{2}{c}{$\begin{array}{c}\text { Before COVID- } \\
\text { 19 Outbreak }\end{array}$} & \multicolumn{2}{c}{$\begin{array}{c}\text { During COVID- } \\
\text { 19 Outbreak }\end{array}$} & \multirow{2}{*}{ p } \\
\cline { 2 - 5 } & $\mathbf{n}$ & $\mathbf{\%}$ & $\mathbf{n}$ & $\mathbf{\%}$ & \\
\hline After each meal & 353 & 34.85 & 342 & 33.76 & \\
Once a day & 471 & 46.50 & 471 & 46.50 & \multirow{2}{*}{0.583} \\
3 times a week & 189 & 18.66 & 200 & 19.74 & \\
\hline ‡Mc Nemar's Test & & & & &
\end{tabular}

\section{Discussion}

To the best of our knowledge, this is one of the first studies to examine the effect of the COVID-19 outbreak on the cariogenic dietary practices of children from an oral health perspective. COVID-19 as a major public health problem with high hypertransmissibility lead to the implementation of social distancing measures that required people to stay indoors and close schools; therefore, the daily activities of numerous students and parents were affected all around the world. It is well-accepted that in order to stay healthy and prevent the disease, an adequate and balanced diet is crucial to improve the immune systems of individuals $(14,15)$. Dietary preferences influence oral health, along with general health and well-being. It is evident that improper nutrition and diet are related to dental caries development in children $(16,17)$.

During the COVID-19 pandemic, the WHO (18) recommended the consumption of unprocessed and fresh foods; nonetheless, it discouraged the intake of foods and beverages rich in salt, fat, and sugar, such as juice drinks with added sugar, fizzy drinks, flavored milk, cookies, cakes, and chocolates (19). Apart from the negative impact on systemic health, food and drink preference affects oral health since dental caries is closely related to diet (20). Dental caries is caused by mineral loss of the hard structures of teeth when plaque $\mathrm{pH}$ decreases below the critical value of 5.5 due to acid production as a result of fermentable carbohydrate metabolism by oral bacteria, such as Streptococcus mutants, and lactobacilli. Cariogenic foods contain fermentable carbohydrates, such as sugars, which decrease the plaque $\mathrm{pH}$ to less than this critical value (21). The dietary practices of individuals should therefore be taken into account in the prevention of dental caries. The high sugar and acid contents of nutrients can cause dental caries and tooth erosion; moreover, they increase the risk of such diseases as overweight, obesity, and type 2 diabetes $(20,22,23)$. Medrano et al. (24) reported unhealthy eating behaviors before the COVID-19 outbreak among 8-16-year-old Spanish schoolchildren; however, they reported improved dietary behaviors during the outbreak. Rodrigo et al. (25) also conducted a study on 1036 Spanish adults, observing an improvement in dietary habits during the quarantine period. Moreover, another study performed by Rodríguez-Pérez et al. (26) in Spain showed healthier dietary practices during the outbreak than prior practices among an adult population. These findings (24-26) were also in agreement with the results of the current study.

On the other hand, Sidor and Rzymski (27) assessed the frequency consumption of particular food products during quarantine among adults in Poland. As reported, participants were found to consume sweets at least every day. Batlle-Bayer et al. (28) reported increased energy intake and reduced quality of nutrition during the COVID-19 outbreak, as compared to before. In the same context, Di Renzo et al. (29) reported that two-thirds of participants increased their consumption of sweets and junk foods and decreased their consumption of vegetables and fruits, in comparison with the time before the COVID-19 outbreak. In another study (30), an increased intake of comfort foods (42.5\%) and salty snacks (23.5\%) was detected among participants during the COVID-19 outbreak. Furthermore, Pietrobelli et al. (31) also reported increased consumption of sugary drinks and potato chips among Italian children during the COVID-19 outbreak. The observed increase in unhealthy food consumption in these studies (27-31) was not in line with the findings of the present study. Ruiz-Roso et al. (32) conducted a study among adolescents aged 10-19 years and reported that sweet food intake increased from $14 \%$ to nearly $20 \%$ among adolescents on a daily basis, which was higher than our findings. In addition, sugar-sweetened beverage intake remained the same in their study, whereas our study found this to be reduced.

Furthermore, $44.82 \%$ of the parents in the present study thought that the cariogenic food consumption frequency of their children increased 
while staying at home during the COVID-19 outbreak. Nonetheless, more than half of the children never consumed fizzy drinks, sugar-sweetened, fruitflavored juices, or flavored milk either before or during the COVID-19 outbreak. Nearly $40 \%$ and $47 \%$ of children never consumed candy or lollipops before and during the outbreak, respectively. The results revealed that the cariogenic food consumption of the children was not high and even decreased during the pandemic. The increased consumption of honey, molasses, and jam can be attributed to the fact that the parents tried to manage their children's needs for sugar with more natural foods. Although not perfect, it is clear that the parents experienced minimal problems in the management of their children's consumption of sugary foods and beverages during the time spent at home. In addition, the usual dietary habits of the children before the COVID-19 outbreak might have affected their dietary attitudes and practices since it is very difficult to suddenly change a habit. Since the children consumed less cariogenic diet before the pandemic, they may have been able to reduce their consumption of cariogenic foods during the pandemic.

Finally, from an oral health perspective, maintaining oral hygiene and a healthy balanced diet is fundamental for oral health. During a pandemic, such as the COVID-19 outbreak, parents should help, support, and improve their children's toothbrushing habits in order to avoid the occurrence of dental caries. During such periods, appropriate oral health management and disease prevention in children is of paramount importance for the prevention of virus transmission and cross-infection. During the COVID19 outbreak, dental offices and dental treatments pose a high risk of contamination due to their aerosol-producing operations. Nearly 50\%, 35\%, and $19 \%$ of all children brushed their teeth at least once a day, after each meal, and three times a week, respectively. It was observed that $65 \%$ of all children did not brush twice daily. Toothbrushing with at least 1, 000 parts per million (ppm) fluoride-containing toothpaste two times a day is effective in the reduction of dental caries in children. It is recommended to use an age-appropriate amount of toothpaste on the toothbrush, such as a smear layer for children younger than three years and a pea-sized amount for children between three and six years of age (33). Oral health professionals should keep educating and supporting parents and children in order to achieve better oral health practices.

\section{Conclusion}

To the best of our knowledge, this is one of the first studies to assess the effect of the COVID-19 outbreak on the cariogenic dietary and toothbrushing practices of children. This web-based study provided data that was difficult to gather otherwise under pandemic conditions. It highlighted the necessity of appropriate dietary and toothbrushing habits during pandemics, such as COVID-19. In the current study, changes in the children's daily routine and quarantine were not observed to increase cariogenic dietary intake, indicating that the parents did not experience much trouble managing their children's consumption of sugary foods and beverages during their time spent at home. The parents were able to control and modify their children's food consumption preferences. Furthermore, no significant differences were detected in the frequency of children's toothbrushing before and after the COVID-19 outbreak. The toothbrushing practices of the participated Turkish children were found to be adequate; however, they could be better.

In conclusion, it is of utmost importance to achieve healthy dietary and toothbrushing habits in order to prevent oral cavities of soft and hard tissues, which can lead to pain and discomfort among children during epidemics. Therefore, both now and in the future, a balanced and healthy diet is essential to protect general and oral health. Continuous and remote oral health education programs, as well as parent support via telephone and social media, must be considered in order to quarantine better oral health for children during such pandemics.

\section{Acknowledgments}

The author thanks all of the parents for their contributions to this study.

\section{Footnotes}

Conflict of Interests: The author declares no conflict of interest.

Ethical Approval: Ethical approval for this crosssectional study was obtained from the Research Ethics Committee of Near East University (NEU/ 2020/79-1084).

Funding/Support: This research received no funding.

\section{References}

1. Mohapatra RK, Pintilie L, Kandi V, Sarangi AK, Das D, Sahu R, et al. The recent challenges of highly contagious COVID-19, causing respiratory infections: symptoms, diagnosis, transmission, possible vaccines, animal models, and immunotherapy. Chem Biol Drug Des. 2020;96(5):1187-208. doi: 10.1111/cbdd.13761. [PubMed: 32654267].

2. Duruk G, Gümüșboğa ZȘ, Colak C. Investigation of Turkish dentists' clinical attitudes and behaviors towards the COVID-19 pandemic: a survey study. Braz Oral Res. 2020;34:e054. doi: 10.1590/1807-3107bor-2020.vol34.0054. [PubMed: 32490887].

3. Güner R, Hasanoğlu I, Aktaş F. COVID-19: Prevention and control measures in community. Turk J Med Sci. 2020;50[SI1):571-7. doi: 10.3906/sag-2004-146. [PubMed: 32293835].

4. Borkowski A, Correa JS, Bundy DA, Burbano C, Hayashi C, Lloyd-Evans E, et al. COVID-19: missing more than a classroom. The impact of school closures on children's nutrition. St. Louis: 
UNICEF Office of Research; 2021.

5. Dunn CG, Kenney E, Fleischhacker SE, Bleich SN. Feeding lowincome children during the Covid-19 pandemic. $N$ Engl J Med. 2020;382(18):e40. doi: 10.1056/NEJMp2005638. [PubMed: 32227759].

6. Food and Agriculture Organization. Maintaining a healthy diet during the COVID-19 pandemic. Rome, Italy: Food and Agriculture Organization; 2020. doi: 10.4060/ca8380en.

7. World Food Programme, Food and Agriculture Organization of the United Nations. Interim guidance note: mitigating the effects of the COVID-19 pandemic on food and nutrition of schoolchildren. Rome, Italy: World Food Programme, Food and Agriculture Organization of the United Nations; 2020. doi: $10.4060 / \mathrm{ca} 8434$ en.

8. Luzzi V, Ierardo G, Bossù M, Polimeni A. Paediatric Oral Health during and after the COVID-19 pandemic. Int J Paediatr Dent. 2021;31(1):20-6. doi: 10.1111/ipd.12737. [PubMed: 33012056].

9. Mathur VP, Dhillon JK. Dental caries: a disease which needs attention. Indian J Pediatr. 2018;85(3):202-6. doi: 10.1007/s12098-017-2381-6. [PubMed: 28643162].

10. Mallineni SK, Innes NP, Raggio DP, Araujo MP, Robertson MD, Jayaraman J. Coronavirus disease (COVID-19): Characteristics in children and considerations for dentists providing their care. Int I Paediatr Dent. 2020;30(3):245-50. doi: 10.1111/ipd.12653. [PubMed: 32250505].

11. Spagnuolo G, De Vito D, Rengo S, Tatullo M. COVID-19 outbreak: an overview on dentistry. Int J Environ Res Public Health. 2020;17(6):2094. doi: 10.3390/ijerph17062094. [PubMed: 32235685].

12. Al-Halabi M, Salami A, Alnuaimi E, Kowash M, Hussein I. Assessment of paediatric dental guidelines and caries management alternatives in the post COVID-19 period. A critical review and clinical recommendations. Eur Arch Paediatr Dent. 2020;21(5):543-56. doi: 10.1007/s40368-02000547-5. [PubMed: 32557183].

13. Hu Z, Yang Z, Li Q Zhang A. The COVID-19 infodemic: infodemiology study analyzing stigmatizing search terms. $J$ Med Internet Res. 2020;22(11):e22639. doi: 10.2196/22639. [PubMed: 33156807]

14. Mahmut ÖZ. Educational policy actions by the ministry of national education in the times of COVID-19 pandemic in Turkey. Kastamonu Eğitim Dergisi. 2020;28(3):1124-9. doi: 10.24106/kefdergi.722280

15. Iddir M, Brito A, Dingeo G, Fernandez Del Campo SS, Samouda $\mathrm{H}$, et al. Strengthening the immune system and reducing inflammation and oxidative stress through diet and nutrition: considerations during the COVID-19 crisis. Nutrients. 2020; 12(6):1562. doi: 10.3390/nu12061562. [PubMed: 32471251].

16. Johansson I, Holgerson PL, Kressin NR, Nunn ME, Tanner AC. Snacking habits and caries in young children. Caries Res. 2010;44(5):421-30. doi: 10.1159/000318569. [PubMed: 20720422].

17. Ong MM, Ong RM, Reyes GK, Sumpaico-Tanchanco LB. Addressing the COVID-19 nutrition crisis in vulnerable communities: applying a primary care perspective. J Prim Care Community Health. 2020;11:2150132720946951. doi: 10.1177/2150132720946951. [PubMed: 32715893]

18. World Health Organization. Feeding babies and young children during the COVID-19 outbreak. Geneva: World Health Organization; 2020.

19. Calcaterra V, Vandoni M, Pellino VC, Cena H. Special attention to diet and physical activity in children and adolescents with obesity during the coronavirus disease-2019 pandemic. Front
Pediatr. 2020;8:407. doi: 10.3389/fped.2020.00407. [PubMed: 32676491].

20. Marshall TA. Dietary implications for dental caries: a practical approach on dietary counseling. Dent Clin North Am. 2019; 63(4):595-605. doi: 10.1016/j.cden.2019.06.005. [PubMed: 31470915]

21. Touger-Decker R, van Loveren C. Sugars and dental caries. $\mathrm{Am} J$ Clin Nutr. 2003;78(4):881S-92S. doi: 10.1093/ajcn/78.4.881S. [PubMed: 14522753].

22. Juul F, Martinez-Steele E, Parekh N, Monteiro CA, Chang VW. Ultra-processed food consumption and excess weight among US adults. $\mathrm{Br} J$ Nutr. 2018;120(1):90-100. doi: 10.1017/S0007114518001046. [PubMed: 29729673].

23. Tahmassebi JF, BaniHani A. Impact of soft drinks to health and economy: a critical review. Eur Arch Paediatr Dent. 2020; 21(1):109-17. doi: 10.1007/s40368-019-00458-0. [PubMed: 31177478].

24. Medrano M, Cadenas-Sanchez C, Oses M, Arenaza L, Amasene $\mathrm{M}$, Labayen I. Changes in lifestyle behaviours during the COVID-19 confinement in Spanish children: a longitudinal analysis from the MUGI project. Pediatr Obes. 2021; 16(4):e12731. doi: 10.1111/ijpo.12731. [PubMed: 32975052].

25. Rodrigo CP, Citores MG, Bárbara GH, Litago FR, Saenz LC, Bartrina JA, et al. Changes in eating habits during the period of confinement due to the COVID-19 pandemic in Spain. Spanish J Community Nutr. 2020;26(2):6.

26. Rodríguez-Pérez C, Molina-Montes E, Verardo V, Artacho R, García-Villanova B, Guerra-Hernández EJ, et al. Changes in dietary behaviours during the COVID-19 outbreak confinement in the Spanish COVIDiet study. Nutrients. 2020;12(6):1730. doi: 10.3390/nu12061730. [PubMed: 32531892].

27. Sidor A, Rzymski P. Dietary Choices and Habits during COVID19 lockdown: experience from Poland. Nutrients. 2020; 12(6):1657. doi: 10.3390/nu12061657. [PubMed: 32503173].

28. Batlle-Bayer L, Aldaco R, Bala A, Puig R, Laso J, Margallo M, et al. Environmental and nutritional impacts of dietary changes in Spain during the COVID-19 lockdown. Sci Total Environ. 2020;748:141410. doi: 10.1016/j.scitotenv.2020.141410. [PubMed: 32798877].

29. Di Renzo L, Gualtieri P, Pivari F, Soldati L, Attinà A, Cinelli G, et al. Eating habits and lifestyle changes during COVID-19 lockdown: an Italian survey. J Transl Med. 2020;18(1):229. doi: 10.1186/s12967-020-02399-5. [PubMed: 32513197].

30. Scarmozzino F, Visioli F. Covid-19 and the subsequent lockdown modified dietary habits of almost half the population in an Italian sample. Foods. 2020;9(5):675. doi: 10.3390/ foods9050675. [PubMed: 32466106].

31. Pietrobelli A, Pecoraro L, Ferruzzi A, Heo M, Faith M, Zoller T, et al. Effects of COVID-19 lockdown on lifestyle behaviors in children with obesity living in Verona, Italy: a longitudinal study. Obesity (Silver Spring). 2020;28(8):1382-5. doi: 10.1002/oby.22861. [PubMed: 32352652].

32. Ruiz-Roso MB, de Carvalho Padilha P, Mantilla-Escalante DC, Ulloa N, Brun P, Acevedo-Correa D, et al. Covid-19 confinement and changes of adolescent's dietary trends in Italy, Spain, Chile, Colombia and Brazil. Nutrients. 2020;12(6):1807. doi: 10.3390/nu12061807. [PubMed: 32560550].

33. International Association of Paediatric Dentistry. APD foundational articles and consensus recommendations: use of fluoride for caries prevention. Available at: URL: http:// www.iapdworld.org/03_use-of-fluoride-for-caries-prevention; 2020. 